\title{
DIOECY AND ITS CORRELATES IN THE FLOWERING PLANTS ${ }^{1}$
}

\author{
SUSANNE S. RENNER ${ }^{2}$ AND ROBERT E. RICKLEFS \\ Institute of Systematic Botany, University of Mainz, Bentzel-Weg 2, D-55099 Mainz, Germany; \\ and Department of Biology, University of Pennsylvania, Philadelphia, Pennsylvania 19104-6018
}

\begin{abstract}
Considerable effort has been spent documenting correlations between dioecy and various ecological and morphological traits for the purpose of testing hypotheses about conditions that favor dioecy. The data analyzed in these studies, with few exceptions, come from local floras, within which it was possible to contrast the subsets of dioecious and nondioecious taxa with regard to the traits in question. However, if there is a strong phylogenetic component to the presence or absence of dioecy, regional sampling may result in spurious associations. Here, we report results of a categorical multivariate analysis of the strengths of various associations of dioecy with other traits over all flowering plants. Families were scored for presence of absence of monoecy or dioecy, systematic position, numbers of species and genera, growth forms, modes of pollination and dispersal, geographic distribution, and trophic status. Seven percent of angiosperm genera ( 959 of 13,500) contain at least some dioecious species, and $\approx 6 \%$ of angiosperm species $(14,620$ of 240,000$)$ are dioecious. The most consistent associations in the data set relate the presence of dioecy to monoecy, wind or water pollination, and climbing growth. At both the family and the genus level, insect pollination is underrepresented among dioecious plants. At the family level, a positive correlation between dioecy and woody growth results primarily from the association between dioecy and climbing growth (whether woody or herbaceous) because neither the tree nor the shrub growth forms alone are consistently correlated with a family's tendency to include dioecious members. Dioecy appears to have evolved most frequently via monoecy, perhaps through divergent adjustments of floral sex ratios between individual plants. Monoecy itself is related to abiotic pollination and climbing growth as revealed by multivariate analysis. Dioecy and monoecy are concentrated in the less advanced superorders of Thorne (1992) and subclasses of Cronquist (1988). The frequency of dioecy found in a local flora therefore reflects the level of dioecy in its particular pool of families as much as, or more than, local selective factors. The positive associations of dioecy with abiotic pollination and monoecy are related to floral developmental and morphological attributes, as is the negative association with bird and bat pollination; the positive association of dioecy with climbing growth is tentatively explained in terms of differential selection for optimal resource allocation to sexual function. If rapid upward growth is at a premium in climbers and if fruit set at least temporarily inhibits growth or requires the production of thicker, more slowly growing stems to support heavy fruits, it might be advantageous to postpone femaleness. If the effect is strong, this may favor male plants.
\end{abstract}

Over the past $15 \mathrm{yr}$ considerable effort has been spent documenting correlations between dioecy and various morphological and ecological traits for the purpose of testing hypotheses about conditions that favor dioecy. Ecological correlates attracted attention in particular because dioecy has proven difficult to explain simply as an outbreeding mechanism in taxa lacking self-incompatibility (for discussions of this issue, see Charlesworth and Charlesworth, 1978; Thomson and Barrett, 1981; Charlesworth, 1985; Thomson and Brunet, 1990). At different spatial and hierarchical scales, dioecy has been associated with, among other attributes, wind pollination (Darwin, 1876; Kerner, 1895; Sporne, 1949; Stebbins, 1951; Kaplan and Mulcahy, 1971; Freeman, Harper, and Ostler, 1980; Muenchow, 1987; Steiner, 1988), monoecy (Yampolsky and Yampolsky, 1922; Lewis, 1942; Westergaard, 1958; McComb, 1966; Lloyd, 1982), perennial growth and lignified secondary xylem, or woodiness (Darwin, 1876; Stebbins, 1950; Baker, 1959; Croat, 1979; Conn, Wentworth, and Blum, 1980; Freeman, Harper, and Ostler, 1980; Fox, 1985; but see Steiner, 1988), fleshy

\footnotetext{
${ }^{1}$ Manuscript received 19 May 1994; revision accepted 23 November 1994.

The authors thank D. Charlesworth, P. Cox, P. Endress, C. Freeman, S. Heard, J. Kohn,- J. Thomson, and K. Bawa for comments on the manuscript; and P. Berry (Onagraceae), H.-J. Esser (Euphorbiaceae), S. Knapp (Solanaceae), J. Kuijt (parasitic angiosperms), C. Ott (Menispermaceae), and J. Rohwer (Lauraceae) for information on dioecy in particular groups.

${ }^{2}$ Author for correspondence.
}

fruits and frugivore-dispersed seeds (Bawa, 1980; Givnish, 1980; Steiner, 1988; Ibarra-Manríquez and Oyama, 1992; but see Fox, 1985; Muenchow, 1987; Thomson and Brunet, 1990), small flowers (Bawa and Opler, 1975; Fox, 1985; Ibarra-Manríquez and Oyama, 1992), white to yellow or greenish flowers (Bawa and Opler, 1975; Muenchow, 1987), water pollination (Cox, 1988), and so-called unspecialized insect pollinators (Bawa and Opler, 1975; Bawa, 1994; contra Renner and Feil, 1993).

While older reports tested the associations between dioecy and particular attributes separately, more recent ones have used multivariate analysis, taking into account correlations among some of the explanatory variables themselves (Fox, 1985; Muenchow, 1987; Steiner, 1988; Ibarra-Manriquez and Oyama, 1992). Some authors have attempted to incorporate phylogenetic information in analyses of the association of dioecy with other traits by looking at the species, genus, and family levels separately or by restricting analyses to monophyletic groups (Hart, 1985; Donoghue, 1989; Cox, 1990, 1993; Lahav-Ginott and Cronk, 1993).

The data analyzed in these studies, with a few exceptions such as Cox's $(1990,1993)$ phylogenetic analyses, all come from local floras. Such locally circumscribed data allow one to contrast the subsets of dioecious and nondioecious taxa with regard to particular ecological and morphological traits of interest. For example, the relationships between a particular floral color or size and dioecy can be analyzed only if floral colors or sizes for the universe of nondioecious species are known. At present, this is pos- 
sible only on a local basis. No study has yet addressed the correlates of dioecy in the flowering plants at large, and some apparent associations among dioecy and particular traits may, therefore, be the result of regional effects, particularly if there is a strong phylogenetic component to the presence or absence of dioecy. As long as such sampling problems remain unrecognized they may result in the introduction of unnecessary ad hoc hypotheses to explain supposed correlations that did not play a causal role in the evolution of dioecy.

Here we report results of a study in which we have determined the relative strengths of various associations between dioecy and particular traits across all flowering plants. Because we use a multivariate approach, the possibility of fortuitous associations among the traits themselves is reduced. Our analysis, to some degree, also takes care of phylogenetic bias because it is not restricted to particular families that happen to dominate local floras (see Steiner, 1988, for a particularly striking example of this effect in the Cape flora of South Africa). It is based on a new compilation of dioecious angiosperm genera and families, the only previous such compilation by Yampolsky and Yampolsky (1922) being outdated. Systematists' views of the phylogenetic relationships within the angiosperms and the circumscription and systematic placement of numerous genera have changed during the past $70 \mathrm{yr}$, new cases of dioecy have been reported, and many others mentioned by Yampolsky and Yampolsky have turned out to be in error. In another paper, the same data set will be used to study the distribution of dioecy in the framework of recently published angiosperm phylogenies (Renner, unpublished data).

Specifically we analyze whether at the family level dioecy is associated with monoecy, particular geographic distributions, wind or water vs. animal pollination, fleshy fruits and, therefore, animal-dispersed vs. abiotically dispersed seeds, or particular growth forms. Because we lacked data for all angiosperms we were unable to address associations between dioecy and small, greenish flowers (Bawa and Opler, 1975; Fox, 1985; Muenchow, 1987; Ibarra-Manríquez and Oyama, 1992) and between dioecy and pollination by small, supposed generalist insects (Bawa, 1994). The former may be a correlate of the association demonstrated below between wind pollination and dioecy, because wind-pollinated flowers are often small and lack attractive coloration; the second is based on the erroneous idea that pollinator smallness is correlated with unspecific pollinator-flower relationships and inefficient (in terms of outcrossing) pollination (Renner and Feil, 1993).

\section{MATERIALS AND METHODS}

This study is based on two data sets, one a data base of dioecious angiosperm genera compiled by searching the literature and by corresponding with specialists (see Acknowledgments), the other a data base of all families of flowering plants. For details of the second compilation see Ricklefs and Renner (1994). The genus and the family data bases contain the following information for each taxon: presence or absence of dioecy, presence or absence of monoecy (in the family data set); position in the angiosperms in terms of the 11 subclasses of Cronquist
(1988) and the 28 superorders of Thorne (1992); total number of genera (in the family data set) and number of dioecious species (in the genus data set); growth forms; modes of pollination and dispersal; geographic distribution; and trophic status. Genera accepted are those of Brummitt (1992); families are those of Cronquist (1988), except that in 18 cases more recent, broader family concepts were accepted. To look at the effects of differences in familial concepts, the data sets were also broken down into the more narrowly circumscribed families of Thorne (1992).

Dioecy and monoecy were scored as present in a family when at least one species in that family is dioecious or monoecious. Particularly in the case of families with few dioecious taxa great care was taken to search the literature for independent confirmation of their dioecious status. Numerous taxa $(\approx 20$ families and $\approx 200$ genera) listed as including dioecious species by Yampolsky and Yampolsky (1922) had to be removed from the data set, either because the supposedly dioecious plants have turned out to be sex-changing, polygamous, monoecious, or gynodioecious, or because of nomenclatural and taxonomic changes. Yampolsky and Yampolsky based their compilation on Engler and Prantl's Natürliche Pflanzenfamilien and the volumes of Engler's Pflanzenreich published by 1912. They concluded that out of the total of 10,113 angiosperm genera then recognized, 972 (9.6\%) comprised dioecious and/or polygamodioecious species. However, their list includes at least $\mathbf{9 0}$ genera since merged with other genera; some, such as Streblus, are listed eight times under different names. There are also 43 unpublished names (nomina nuda), the identity of which is obscure. Several other genera, from a modern systematic viewpoint, are completely misplaced as to family. Conversely, $\simeq 170$ additional dioecious genera and many additional families were added either because of newly discovered instances of dioecy or because of taxonomic changes, such as narrower modern family concepts. Our data set contains 959 genera that include dioecious species.

Most dioecious genera comprise only dioecious species; however, 325 of the 959 genera have more than one mating system, and for them numbers of dioecious species had to be estimated from figures given in recent literature, usually floras. Statements such as "rarely dioecious" or "occasionally dioecious" were scored conservatively as at least one dioecious species, while "commonly dioecious" was scored as $50 \%$ dioecious. Species numbers are not used in the analyses.

Growth forms were taken from floras and accounts of particular modes of growth, such as Gentry (1991) for climbers, while geographic distributions are from Mabberley (1987), except where more recent systematic work was available. Growth form was tabulated as presence or absence of trees, shrubs, herbs, or climbers (whether woody or herbaceous).

Pollination and dispersal modes were assessed from descriptions of the flowers and fruits of each taxon in various floristic and monographic sources (for details, see Ricklefs and Renner, 1994). In both data sets, the categories were 1) abiotic, 2) biotic, and 3) variable, the last meaning both types of pollination or dispersal present in different species within the genus or family. In the generic data set, pollination mode was additionally scored as 1) 
wind, 2) water, 3) insects, 4) bats, 5) birds, 6) variable, or 7) unknown. Data on the pollination of many dioecious taxa had already been compiled in connection with an earlier review of the literature (Renner and Feil, 1993). A few additional autecological studies have since been published (e.g., Kato, 1993), and there are several systematic reviews (Dobat and Peikert-Holle, 1985; Cox, 1988; Kubitzki, Rohwer, and Bittrich, 1993; Webster, $1994 a, b)$. For many of the remaining genera, pollination by either wind or insects could be assessed from floral structure, with particular weight being given to the presence or absence of nectaries. All fleshy fruits, as well as indehiscent large dry fruits, were scored as being adapted for animal dispersal. Some small dry fruits scored as abiotically dispersed may have seeds initially dispersed ballistically and then biotically (by ants); it is unlikely, however, that this group introduces a large error into the data. Where descriptions of floral structures and/or fruits were insufficient to assess reproductive modes, the condition was left unscored in the generic data set; all families could be scored.

For the family-level analysis, geographic distribution was coded as present or absent in tropical latitudes and present or absent in temperate latitudes. The category "tropical" includes all families whose distributions include either low or high elevations in the tropics; "temperate" includes all families whose distributions include temperate or boreal zones-generally, zones with frost. The distributions of the dioecious genera were scored in considerable detail for future analysis because many genera with variable mating systems also have their dioecious species confined to a particular region. For example, in Asperula (Rubiaceae), the 16 Australian species are dioecious while the Mediterranean species are hermaphroditic.

Each variable was scored as 0 (absent) or 1 (present). Within each of the categories of variables (distribution, mating system, pollination, dispersal, growth form, trophic status) each family had to have a score of 1 for at least one of the variables but could also have a score of 1 for all of them. None could have scores of 0 for all of them. For some of the analyses, the families were also divided into two groups based on number of genera: size $=0$, fewer than 5 genera; size $=1,5$ or more genera.

In order to examine the relationship of dioecy to all variables simultaneously, categorical multivariate contingency analyses (SAS Institute, Inc., 1988, CATMOD procedure) were performed in which the presence or absence of dioecy was related to presence or absence of all the other variables in the data set. Categorical models take into account associations among the independent (predictor) variables and reveal the unique statistical relationships between dioecy and other variables in the data set. When applied at the taxonomic level of family, this approach identifies the association of traits within taxa but does not imply that a pair of associated traits necessarily occurs in the same genus or species. Indeed dioecy and monoecy cannot co-occur in a single species and hence their association could only be identified by a higher-level analysis. A difficulty with this approach is that two traits may be associated because each is more likely to be represented in families with large numbers of species. We tried to deal with this difficulty in two ways: first, we repeated the analyses using only small families (less than five genera per family), which heightens the likelihood of co-occurrence of the variables in the same genus or species; second, we also examined associations at the genus level where possible.

The statistical significance of each of the variables is evaluated by a $\chi^{2}$ with its associated probability. Each model has a likelihood ratio (LR) which, if significant, indicates additional structure in the data set not accounted for by the model. Initial models included no interactions. Nonsignificant variables were deleted from the model and when LR $\chi^{2}$ values were significant, interactions were added by trial and error to arrive at a model with a nonsignificant LR $\chi^{2}$. Because monoecy is a mating system that may facilitate the evolution of dioecy (see below), these models were run both with $(+M)$ and without $(-M)$ monoecy as a variable to isolate the effects of ecological interactions on dioecy.

\section{RESULTS}

Out of the total of 13,479 genera (Brummitt, 1992), at least 959 (7.1\%) contain dioecious species; if Thorne's (1992) estimate of 12,650 genera for the angiosperms is accepted, that percentage is $7.6 \%$. A conservative estimate of the number of dioecious species is 14,620 or $6 \%$ of an assumed total of 240,000 species of flowering plants. Of a conservatively circumscribed 365 families of angiosperms (essentially the families of Cronquist, 1988; see Materials and Methods), 157 (43\%) contain dioecious members. Of Thorne's (1992) more narrowly defined 437 families, $167(38 \%)$ have dioecious members.

In the following we first present results of analyses performed using the family-level data set (Tables 1-12); this is followed by results based on genus-level data (Tables 13 and 14).

Contingency analyses relating each variable individually to dioecy are presented in Table 1 . Variables that are significantly and strongly associated with dioecy are, in order of the strength of their correlation, monoecy, climbing growth form, biotic dispersal, abiotic pollination, shrub growth form, and tropical distribution.

Categorical models are presented in Table 2. The strongest effects in an initial model (no interactions) were monoecy, climbing growth form, biotic dispersal, abiotic pollination, and tropical distribution. The individual association of shrubby growth with dioecy evidently was subsumed in this model through correlation with other variables. In this analysis, the likelihood ratio was significant, indicating additional structure in the data set in the form of interactions. A series of models with various two-way interaction terms were then run. The only significant interaction was abiotic pollination $\times$ monoecy. When this interaction was included and nonsignificant effects were deleted from the model, the likelihood ratio became nonsignificant (Table 2 , model $+M$ ). Thus, several factors contribute independently to the presence of dioecy within a family, in descending order of importance: monoecy, tropical distribution, abiotic pollination, shrub growth form, and climbing growth form. In addition, however, monoecy interacts with abiotic pollination in contributing to dioecy (Table 3). When monoecy was excluded from the categorical analysis (Table 2 , model $-M$ ), 
TABLE 1. Family-level relationship of presence (in 157 families) or absence (in 208 families) of dioecy to each of the variables.

\begin{tabular}{|c|c|c|c|c|c|c|}
\hline \multirow[b]{3}{*}{$\begin{array}{c}\text { Category and } \\
\text { variable }\end{array}$} & \multicolumn{4}{|c|}{ Number of families } & \multirow[b]{3}{*}{$\chi^{2 \mathrm{a}}$} & \multirow[b]{3}{*}{$P$} \\
\hline & \multicolumn{2}{|c|}{ Variable absent } & \multicolumn{2}{|c|}{ Variable present } & & \\
\hline & $\begin{array}{l}\text { Dioecy } \\
\text { absent }\end{array}$ & $\begin{array}{l}\text { Dioecy } \\
\text { present }\end{array}$ & $\begin{array}{l}\text { Dioecy } \\
\text { absent }\end{array}$ & $\begin{array}{l}\text { Dioecy } \\
\text { present }\end{array}$ & & \\
\hline Monoecy & 179 & 54 & 29 & 103 & 107.6 & 0.000 \\
\hline \multicolumn{7}{|l|}{ Distribution } \\
\hline $\begin{array}{l}\text { Tropical } \\
\text { Temperate }\end{array}$ & $\begin{array}{r}41 \\
111\end{array}$ & $\begin{array}{l}12 \\
80\end{array}$ & $\begin{array}{r}167 \\
97\end{array}$ & $\begin{array}{r}145 \\
77\end{array}$ & $\begin{array}{r}11.2 \\
0.2\end{array}$ & $\begin{array}{l}0.001 \\
0.648\end{array}$ \\
\hline \multicolumn{7}{|l|}{ Pollination } \\
\hline $\begin{array}{l}\text { Abiotic } \\
\text { Biotic }\end{array}$ & $\begin{array}{r}177 \\
24\end{array}$ & $\begin{array}{r}104 \\
33\end{array}$ & $\begin{array}{r}31 \\
184\end{array}$ & $\begin{array}{r}53 \\
124\end{array}$ & $\begin{array}{r}17.9 \\
6.0\end{array}$ & $\begin{array}{l}0.000 \\
0.014\end{array}$ \\
\hline \multicolumn{7}{|l|}{ Dispersal } \\
\hline $\begin{array}{l}\text { Abiotic } \\
\text { Biotic }\end{array}$ & $\begin{array}{r}55 \\
117\end{array}$ & $\begin{array}{l}59 \\
46\end{array}$ & $\begin{array}{r}153 \\
91\end{array}$ & $\begin{array}{r}98 \\
111\end{array}$ & $\begin{array}{r}5.1 \\
26.8\end{array}$ & $\begin{array}{l}0.023 \\
0.000\end{array}$ \\
\hline \multicolumn{7}{|l|}{ Growth form } \\
\hline $\begin{array}{l}\text { Herb } \\
\text { Shrub } \\
\text { Tree } \\
\text { Climber }\end{array}$ & $\begin{array}{l}103 \\
119 \\
118 \\
157\end{array}$ & $\begin{array}{l}87 \\
59 \\
72 \\
72\end{array}$ & $\begin{array}{r}105 \\
89 \\
90 \\
51\end{array}$ & $\begin{array}{l}70 \\
98 \\
85 \\
85\end{array}$ & $\begin{array}{r}1.2 \\
13.9 \\
4.2 \\
33.8\end{array}$ & $\begin{array}{l}0.264 \\
0.000 \\
0.039 \\
0.000\end{array}$ \\
\hline $\begin{array}{l}\text { Parasite } \\
\text { Size of family }\end{array}$ & $\begin{array}{l}203 \\
130\end{array}$ & $\begin{array}{r}149 \\
53\end{array}$ & $\begin{array}{r}5 \\
78\end{array}$ & $\begin{array}{r}8 \\
104\end{array}$ & $\begin{array}{r}1.9 \\
30.0\end{array}$ & $\begin{array}{l}0.172 \\
0.000\end{array}$ \\
\hline
\end{tabular}

${ }^{a} \chi^{2}$ is the likelihood ratio $\chi^{2}$ value.

abiotic pollination and climbing growth form remained strong correlates of dioecy.

Because, on average, large families contain more dioecious taxa than do small families (Table 1), the data were split into two sets having nearly equal numbers of families based on number of genera per family (less than five, and five or more). Among small families, the strongest individual effects are monoecy and the pollination and dispersal variables, with dioecy less often present in families with biotic pollination and abiotic dispersal and more often present in families with abiotic pollination
TABLE 3. Contingency table of the effects of abiotic pollination and biotic dispersal on presence of dioecy. All families are included in the analysis. Ratios are numbers of families with dioecy over total number of families. ${ }^{a}$

\begin{tabular}{cccc}
\hline \hline & \multicolumn{2}{c}{ Monoecy } & \\
\cline { 2 - 3 } & Absent & Present & Total \\
\hline Abiotic pollination & & & \\
Absent & $33 / 198$ & $71 / 83$ & $104 / 281$ \\
& $(17 \%)$ & $(86 \%)$ & $(37 \%)$ \\
Present & $21 / 35$ & $32 / 49$ & $53 / 84$ \\
& $(60 \%)$ & $(65 \%)$ & $(63 \%)$ \\
Total & $54 / 233$ & $103 / 132$ & $157 / 365$ \\
& $(23 \%)$ & $(78 \%)$ & $(43 \%)$ \\
\hline
\end{tabular}

a The relationship between monoecy and dioecy in the absence of abiotic pollination had LR $\chi^{2}=123.4, P<0.001$, and in the presence of abiotic pollination, $\mathrm{LR} \chi^{2}=0.2, P=0.62$.

and biotic dispersal (Table 4, but see below). In addition, dioecy is less likely in families containing herbs and more likely in families containing shrubs and trees. A categorical model excluding nonsignificant effects and including the interaction of monoecy with abiotic pollination had a nonsignificant likelihood-ratio and revealed abiotic pollination, biotic dispersal, monoecy, and climbing growth to be the only significant effects (Table 5, Model $+M$ ). Much of the information contributed by monoecy is contained in the monoecy $\times$ abiotic pollination interaction (Table 6). When monoecy was excluded from the analysis (Table 5, Model -M), we could not find a wholly satisfactory model (LR, $P=0.034)$, but the same variables (abiotic pollination, biotic dispersal, climbing growth) remained significant.

Among large families (Table 7), the strongest effects were monoecy, biotic dispersal, climbing and shrub growth forms, and tropical distribution, with abiotic dispersal exerting a weak negative effect. A categorical model showed monoecy and tropical distribution to be the only signif-

TABLE 2. Categorical models of the relationship at the family level between dioecy and the independent variables in this analysis.

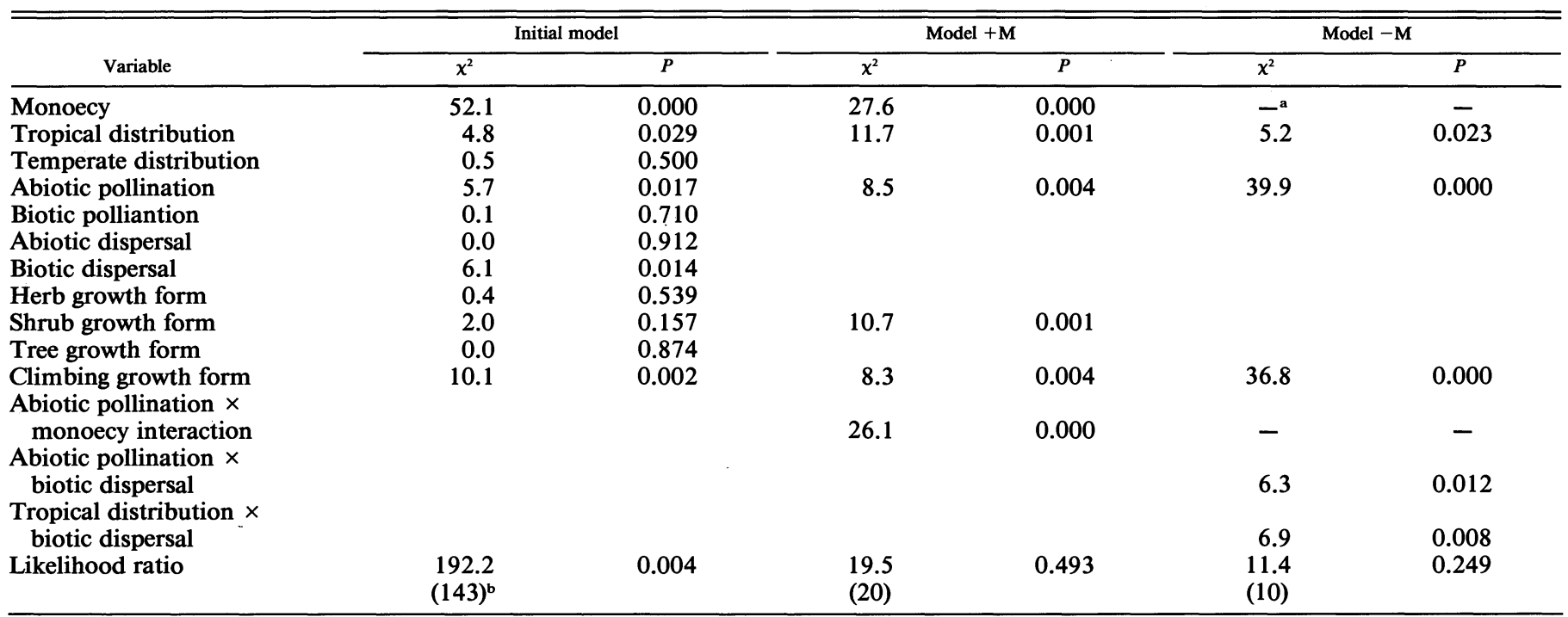

a Variable not included in analysis.

b Degrees of freedom for likelihood ratio. 
TABLE 4. Relationship of presence (in 53 families) or absence (in 130 families) of dioecy to each of the variables independently among small families $(<5$ genera)

\begin{tabular}{|c|c|c|c|c|c|c|}
\hline \multirow[b]{3}{*}{$\begin{array}{c}\text { Category and } \\
\text { variable }\end{array}$} & \multicolumn{4}{|c|}{ Number of families } & \multirow[b]{3}{*}{$x^{2 a}$} & \multirow[b]{3}{*}{$P$} \\
\hline & \multicolumn{2}{|c|}{ Variable absent } & \multicolumn{2}{|c|}{ Variable present } & & \\
\hline & $\begin{array}{l}\text { Dioecy } \\
\text { absent }\end{array}$ & $\begin{array}{l}\text { Dioecy } \\
\text { present }\end{array}$ & $\begin{array}{l}\text { Dioecy } \\
\text { absent }\end{array}$ & $\begin{array}{l}\text { Dioecy } \\
\text { present }\end{array}$ & & \\
\hline Monoecy & 113 & 31 & 17 & 22 & 16.8 & 0.000 \\
\hline \multicolumn{7}{|l|}{ Distribution } \\
\hline $\begin{array}{l}\text { Tropical } \\
\text { Temperate }\end{array}$ & $\begin{array}{l}30 \\
74\end{array}$ & $\begin{array}{r}9 \\
28\end{array}$ & $\begin{array}{r}100 \\
56\end{array}$ & $\begin{array}{l}44 \\
25\end{array}$ & $\begin{array}{l}0.9 \\
0.3\end{array}$ & $\begin{array}{l}0.35 \\
0.61\end{array}$ \\
\hline \multicolumn{7}{|l|}{ Pollination } \\
\hline $\begin{array}{l}\text { Abiotic } \\
\text { Biotic }\end{array}$ & $\begin{array}{r}107 \\
20\end{array}$ & $\begin{array}{l}20 \\
23\end{array}$ & $\begin{array}{r}23 \\
110\end{array}$ & $\begin{array}{l}33 \\
30\end{array}$ & $\begin{array}{l}33.8 \\
15.4\end{array}$ & $\begin{array}{l}0.000 \\
0.000\end{array}$ \\
\hline \multicolumn{7}{|l|}{ Dispersal } \\
\hline $\begin{array}{l}\text { Abiotic } \\
\text { Biotic }\end{array}$ & $\begin{array}{l}46 \\
76\end{array}$ & $\begin{array}{l}30 \\
21\end{array}$ & $\begin{array}{l}84 \\
54\end{array}$ & $\begin{array}{l}23 \\
32\end{array}$ & $\begin{array}{l}7.0 \\
5.4\end{array}$ & $\begin{array}{l}0.009 \\
0.020\end{array}$ \\
\hline \multicolumn{7}{|l|}{ Growth form } \\
\hline $\begin{array}{l}\text { Herb } \\
\text { Shrub } \\
\text { Tree } \\
\text { Climber }\end{array}$ & $\begin{array}{r}75 \\
80 \\
71 \\
117\end{array}$ & $\begin{array}{l}40 \\
25 \\
20 \\
43\end{array}$ & $\begin{array}{l}55 \\
50 \\
59 \\
13\end{array}$ & $\begin{array}{l}13 \\
28 \\
33 \\
10\end{array}$ & $\begin{array}{l}5.3 \\
3.2 \\
4.3 \\
2.5\end{array}$ & $\begin{array}{l}0.021 \\
0.076 \\
0.038 \\
0.112\end{array}$ \\
\hline
\end{tabular}

${ }^{a} \chi^{2}$ is the likelihood ratio $\chi^{2}$.

icant effects, but there was a strong interaction between biotic dispersal and abiotic pollination (Table 8, Model +Ma). Climbing growth form was not significant.

The interaction effect of abiotic pollination and biotic dispersal in large families can be visualized by examining the contingency table relating presence or absence of dioecy to combinations of presence and absence of each of these variables (Table 9). Biotic dispersal and abiotic pollination were not individually significant effects. However, families with neither of these attributes included fewer dioecious taxa than families with either one or both of them. The same is true of the interaction between abiotic pollination and monoecy (Table 10 ), which also makes a suitable categorical model (Table 8, model $+\mathrm{Mb}$ ). When monoecy was deleted from the categorical model for large families, abiotic pollination, tropical distribution, and climbing growth form were significant effects, along with the abiotic pollination $\times$ biotic dispersal interaction (Table 8, model $-\mathrm{M}$ ).

To summarize the categorical analyses, the most con-

TABLE 5. Categorical models for small families ( $<5$ genera) of the relationship between dioecy and the independent variables in this analysis.

\begin{tabular}{|c|c|c|c|c|}
\hline \multirow[b]{2}{*}{ Variable } & \multicolumn{2}{|c|}{ Model + M } & \multicolumn{2}{|c|}{ Model -M } \\
\hline & $x^{2}$ & $P$ & $x^{2}$ & $P$ \\
\hline Monoecy & 6.2 & 0.013 & - & - \\
\hline Abiotic pollination & 13.4 & 0.000 & 12.3 & 0.000 \\
\hline Biotic dispersal & 7.8 & 0.005 & 9.8 & 0.002 \\
\hline Climbing growth form & 4.3 & 0.039 & 9.5 & 0.002 \\
\hline $\begin{array}{l}\text { Abiotic pollination } \times \\
\text { monoecy interaction } \\
\text { Abiotic pollination } \times\end{array}$ & 4.8 & 0.028 & - & - \\
\hline climbing growth form & & & 4.0 & 0.046 \\
\hline $\begin{array}{l}\text { Likelihood ratio } \\
\text { (df) }\end{array}$ & $\begin{array}{l}15.6 \\
(10)\end{array}$ & 0.111 & $\begin{array}{c}10.4 \\
(4)\end{array}$ & 0.034 \\
\hline
\end{tabular}

TABLE 6. Contingency table of the effects of abiotic pollination and biotic dispersal on presence of dioecy. Only small families $(<5$ genera) are included in the analysis. Ratios are number of dioecious families over total number of families. ${ }^{\mathrm{a}}$

\begin{tabular}{cccc}
\hline & \multicolumn{2}{c}{ Monoecy } & \\
\cline { 2 - 3 } & Absent & Present & Total \\
\hline Abiotic pollination & & & \\
Absent & $13 / 114$ & $7 / 13$ & $20 / 127$ \\
& $(11 \%)$ & $(54 \%)$ & $(16 \%)$ \\
Present & $18 / 30$ & $15 / 26$ & $33 / 56$ \\
& $(60 \%)$ & $(58 \%)$ & $(59 \%)$ \\
Total & $31 / 144$ & $22 / 39$ & $53 / 183$ \\
& $(22 \%)$ & $(56 \%)$ & $(29 \%)$ \\
\hline
\end{tabular}

a The relationship between monoecy and dioecy in the absence of abiotic pollination had LR $\chi^{2}=11.8, P<0.001$, and in the presence of abiotic pollination, LR $\chi^{2}=0.0, P=0.86$.

sistent associations in the data set relate the presence of dioecy within a family to monoecy, climbing growth, abiotic pollination, and biotic dispersal; tropical distribution is associated with dioecy only in large families.

Because monoecy was such an important factor in association with dioecy, we examined the relationship of monoecy itself to the distribution of other variables (excluding dioecy) within families (Table 11). Several factors had significant associations with monoecy: climbing growth $(+)$, abiotic pollination $(+)$, biotic pollination $(-)$, biotic dispersal $(+)$, and temperate distribution $(+)$. A categorical model of the dependence of monoecy on other variables produced the following results: abiotic pollination $\left(\chi^{2}=46.8, P=0.000\right)$, climbing growth (36.9, $0.000)$, temperate distribution $(3.9,0.049)$, abiotic pollination $\times$ biotic dispersal interaction $(11.2,0.001)$, likelihood ratio (12 df, 23.4, 0.025). Among families including taxa with abiotic pollination, presence or absence of biotic dispersal had no influence on monoecy $(60.9 \%$ vs. $55.3 \%$,

TABLE 7. Relationship among large families ( $\geq 5$ genera) of presence (in 104 families) or absence (in 78 families) of dioecy to each of the variables.

\begin{tabular}{|c|c|c|c|c|c|c|}
\hline \multirow[b]{3}{*}{$\begin{array}{l}\text { Category and } \\
\text { variable }\end{array}$} & \multicolumn{4}{|c|}{ Number of families } & \multirow[b]{3}{*}{$x^{2 a}$} & \multirow[b]{3}{*}{$P$} \\
\hline & \multicolumn{2}{|c|}{ Variable absent } & \multicolumn{2}{|c|}{ Variable present } & & \\
\hline & $\begin{array}{l}\text { Dioecy } \\
\text { absent }\end{array}$ & $\begin{array}{l}\text { Dioecy } \\
\text { present }\end{array}$ & $\begin{array}{l}\text { Dioecy } \\
\text { absent }\end{array}$ & $\begin{array}{l}\text { Dioecy } \\
\text { present }\end{array}$ & & \\
\hline Monoecy & 66 & 23 & 12 & 81 & 75.3 & 0.000 \\
\hline \multicolumn{7}{|l|}{ Distribution } \\
\hline $\begin{array}{l}\text { Tropical } \\
\text { Temperate }\end{array}$ & $\begin{array}{l}11 \\
37\end{array}$ & $\begin{array}{r}3 \\
52\end{array}$ & $\begin{array}{l}67 \\
41\end{array}$ & $\begin{array}{r}101 \\
52\end{array}$ & $\begin{array}{l}8.1 \\
0.1\end{array}$ & $\begin{array}{l}0.005 \\
0.73\end{array}$ \\
\hline \multicolumn{7}{|l|}{ Pollination } \\
\hline $\begin{array}{l}\text { Abiotic } \\
\text { Biotic }\end{array}$ & $\begin{array}{r}70 \\
4\end{array}$ & $\begin{array}{l}84 \\
10\end{array}$ & $\begin{array}{r}8 \\
74\end{array}$ & $\begin{array}{l}20 \\
94\end{array}$ & $\begin{array}{l}2.9 \\
1.3\end{array}$ & $\begin{array}{l}0.09 \\
0.25\end{array}$ \\
\hline \multicolumn{7}{|l|}{ Dispersal } \\
\hline $\begin{array}{l}\text { Abiotic } \\
\text { Biotic }\end{array}$ & $\begin{array}{r}9 \\
41\end{array}$ & $\begin{array}{l}29 \\
25\end{array}$ & $\begin{array}{l}69 \\
37\end{array}$ & $\begin{array}{l}75 \\
79\end{array}$ & $\begin{array}{r}7.6 \\
15.7\end{array}$ & $\begin{array}{l}0.006 \\
0.000\end{array}$ \\
\hline \multicolumn{7}{|l|}{ Growth form } \\
\hline $\begin{array}{l}\text { Herb } \\
\text { Shrub } \\
\text { Tree } \\
\text { Climber }\end{array}$ & $\begin{array}{l}28 \\
39 \\
47 \\
40\end{array}$ & $\begin{array}{l}47 \\
34 \\
52 \\
29\end{array}$ & $\begin{array}{l}50 \\
39 \\
31 \\
38\end{array}$ & $\begin{array}{l}57 \\
70 \\
52 \\
75\end{array}$ & $\begin{array}{r}1.6 \\
5.6 \\
1.9 \\
10.4\end{array}$ & $\begin{array}{l}0.21 \\
0.018 \\
0.17 \\
0.001\end{array}$ \\
\hline
\end{tabular}

${ }^{a} \chi^{2}$ is the likelihood ratio $\chi^{2}$. 
TABLE 8. Categorical models for large families of the relationship between dioecy and the independent variables in this analysis.

\begin{tabular}{|c|c|c|c|c|c|c|}
\hline \multirow[b]{2}{*}{ Variable } & \multicolumn{2}{|c|}{ Model +Ma } & \multicolumn{2}{|c|}{ Model + Mb } & \multicolumn{2}{|c|}{ Model -M } \\
\hline & $x^{2}$ & $P$ & $\overline{x^{2}}$ & $P$ & $\chi^{2}$ & $P$ \\
\hline Monoecy & 48.9 & 0.000 & 20.9 & 0.000 & - & - \\
\hline Tropical distribution & 4.2 & 0.040 & 12.4 & 0.000 & 7.6 & 0.006 \\
\hline Abiotic pollination & & & & & 9.7 & 0.002 \\
\hline Climbing growth form & & & & & 5.8 & 0.017 \\
\hline Abiotic pollination $x$ & & & & & & \\
\hline Biotic dispersal & 14.7 & 0.000 & & & 19.9 & 0.000 \\
\hline Abiotic pollination $\times$ & & & & & & \\
\hline Monoecy interaction & & & 7.1 & 0.008 & - & - \\
\hline $\begin{array}{l}\text { Likelihood ratio } \\
\text { (df) }\end{array}$ & $\begin{array}{l}13.3 \\
(12)\end{array}$ & 0.360 & $\begin{array}{l}3.5 \\
(5)\end{array}$ & 0.360 & $\begin{array}{r}9.8 \\
(10)\end{array}$ & 0.455 \\
\hline
\end{tabular}

$\left.\chi^{2}=0.3, P=0.60\right)$. Among families lacking abiotic pollination, presence of biotic dispersal increased the likelihood of monoecy $\left(39.0 \%\right.$ vs. $16.2 \%, \chi^{2}=17.9, P<$ 0.001 ).

Climbing growth, whether herbaceous or woody, also was an important, and unexpected, factor in association with dioecy, and so we examined the relationship of this growth form to the distribution of other variables within families (Table 12). Significant associations were: dioecy $(+)$, tropical distribution $(+)$, monoecy $(+)$, biotic dispersal (+), shrub growth form $(+)$, biotic pollination $(+)$, and abiotic pollination $(-)$. A categorical model of the dependence of climbing growth on other variables produced the following results: shrubby growth $\left(\chi^{2}=26.5\right.$, $P=0.000)$, herbaceous growth $(21.0,0.000)$, biotic dispersal $(8.3,0.004)$, monoecy $(8.1,0.004)$, abiotic pollination (5.2, 0.022), likelihood-ratio ( $22 \mathrm{df}, 24.9,0.30$ ). In addition, there were two strong interactions: herb $\times$ shrub growth form $(19.0,0.000)$ and abiotic pollination $\times$ monoecy $(6.8,0.009)$.

The following sections present results based on the genus-level dioecy data set. Detailed global comparisons between the dioecious genera and the remainder of the angiosperm genera were not feasable. However, because this is the first compilation of dioecy in the angiosperms since Yampolsky and Yampolsky (1922) and Charlesworth (1985) and because the data are suggestive of several trends among dioecious taxa, such as the likely overrepresentation of heterotrophism (see below), we hope that presenting these data here will stimulate further data collection and eventual multivariate analyses on the generic level.

TABLE 9. Contingency table of the effects of abiotic pollination and biotic dispersal on presence of dioecy. Only large families $(\geq 5$ genera) are included in the analysis. Ratios are numbers of dioecious families over total number of families.

\begin{tabular}{cccc}
\hline \hline & \multicolumn{2}{c}{ Biotic dispersal } & \\
\cline { 2 - 3 } & Absent & Present & Total \\
\hline Abiotic pollination & & & \\
Absent & $14 / 53$ & $70 / 101$ & $84 / 154$ \\
& $(26 \%)$ & $(69 \%)$ & $(55 \%)$ \\
Present & $11 / 13$ & $9 / 15$ & $20 / 28$ \\
& $(85 \%)$ & $(60 \%)$ & $(71 \%)$ \\
Total & $25 / 66$ & $79 / 116$ & $104 / 182$ \\
& $(38 \%)$ & $(68 \%)$ & $(57 \%)$ \\
\hline
\end{tabular}

TABLE 10. Contingency table of the effects of abiotic pollination and monoecy on presence of dioecy. Only large families ( $\geq 5$ genera) are included in the analysis. Ratios are numbers of dioecious families over total number of families. ${ }^{a}$

\begin{tabular}{lccc}
\hline \hline & \multicolumn{2}{c}{ Monoecy } & \\
\cline { 2 - 3 } & Absent & Present & Total \\
\hline Abiotic pollination & & & \\
Absent & $20 / 84$ & $64 / 70$ & $84 / 154$ \\
& $(24 \%)$ & $(91 \%)$ & $(55 \%)$ \\
Present & $3 / 5$ & $17 / 23$ & $20 / 28$ \\
& $(60 \%)$ & $(74 \%)$ & $(71 \%)$ \\
Total & $23 / 89$ & $81 / 93$ & $104 / 182$ \\
& $(26 \%)$ & $(87 \%)$ & $(57 \%)$ \\
\hline
\end{tabular}

a The relationship between monecy and dioecy in the absence of abiotic pollination had LR $\chi^{2}=79.1, P<0.001$, and in the presence of abiotic pollination, $\mathrm{LR} \chi^{2}=0.4, P=0.54$.

Dioecy and phylogeny-Dioecy is slightly more common among dicot genera than among monocot genera (8.2\% vs. $\left.5.1 \% ; \chi^{2}=30, P<0.001\right)$. It occurs in 24 of the 28 superorders of Thorne (Table 13) and in each of the six dicot and five monocot subclasses of Cronquist (1988). Because some of Cronquist's subclasses are poorly defined and probably polyphyletic, the following analysis concentrates on Thorne's superorders, which because of their narrower circumscription stand a better chance of being monophyletic.

Among the 14 dicot superorders having $>100$ genera the distribution of dioecious genera is extremely heterogeneous $\left(\chi^{2}{ }_{13}=909, P<0.0001\right)$. In absolute numbers, most dioecious genera are found among Thorne's Malvanae (208), his Magnolianae (134), Violanae (90), Rutanae (71), Commelinanae (62), Theanae (58), and Gentiananae (49). In relative terms, dioecy is concentrated in monocotyledonous Pandananae (100\%), Alismatanae (47\%), and Triuridanae (25\%) and the dicotyledonous Rafflesianae (80\%), Magnolianae (29\%), and Malvanae (28\%). The Magnolianae and Malvanae are thus among the most important dioecious clades, in both relative and absolute terms. This is mainly due to a few dioecy-rich families, such as the Lauraceae, Menispermaceae, Myristicaceae, and Monimiaceae in the first superorder and the Euphorbiaceae, Moraceae, and Urticaceae in the sec-

TABLE 11. Family-level relationships of the presence (in 132 families) or absence (in 233 families) of monoecy to each of the other variables.

\begin{tabular}{|c|c|c|c|c|c|c|}
\hline \multirow[b]{2}{*}{ Variable } & \multicolumn{2}{|c|}{ Variable absent } & \multicolumn{2}{|c|}{ Variable present } & \multirow[b]{2}{*}{$\chi^{2 \mathrm{a}}$} & \multirow[b]{2}{*}{$P$} \\
\hline & $\begin{array}{l}\text { Mon- } \\
\text { oecy } \\
\text { absent }\end{array}$ & $\begin{array}{c}\text { Mon- } \\
\text { oecy } \\
\text { present }\end{array}$ & $\begin{array}{l}\text { Mon- } \\
\text { oecy } \\
\text { absent }\end{array}$ & $\begin{array}{c}\text { Mon- } \\
\text { oecy } \\
\text { present }\end{array}$ & & \\
\hline Tropical distribution & 40 & 13 & 193 & 119 & 3.8 & 0.057 \\
\hline Temperate distribution & 132 & 59 & 101 & 73 & 4.8 & 0.028 \\
\hline Abiotic pollination & 198 & 83 & 35 & 49 & 22.5 & 0.000 \\
\hline Biotic pollination & 26 & 31 & 207 & 101 & 9.4 & 0.002 \\
\hline Abiotic dispersal & 70 & 44 & 163 & 88 & 0.4 & 0.516 \\
\hline Biotic dispersal & 116 & 47 & 117 & 85 & 6.9 & 0.009 \\
\hline Herb growth form & 130 & 60 & 103 & 72 & 3.6 & 0.057 \\
\hline Shrub growth form & 119 & 59 & 114 & 73 & 1.4 & 0.241 \\
\hline Tree growth form & 123 & 67 & 110 & 65 & 0.1 & 0.709 \\
\hline Climbing growth form & 168 & 61 & 65 & 71 & 23.9 & 0.000 \\
\hline Parasite habit & 226 & 126 & 7 & 6 & 0.6 & 0.452 \\
\hline
\end{tabular}

${ }^{a} \chi^{2}$ is the likelihood ratio $\chi^{2}$ value. 
TABLE 12. Family-level relationships of the presence (in 136 families) or absence (in 229 families) of climbing growth form to each of the other variables.

\begin{tabular}{|c|c|c|c|c|c|c|}
\hline \multirow[b]{2}{*}{ Variable } & \multicolumn{2}{|c|}{ Variable absent } & \multicolumn{2}{|c|}{ Variable present } & \multirow[b]{2}{*}{$x^{2 \mathrm{a}}$} & \multirow[b]{2}{*}{$P$} \\
\hline & $\begin{array}{l}\text { Climb- } \\
\text { ers } \\
\text { absent }\end{array}$ & $\begin{array}{c}\text { Climb- } \\
\text { ers } \\
\text { present }\end{array}$ & $\begin{array}{c}\text { Climb- } \\
\text { ers } \\
\text { absent }\end{array}$ & $\begin{array}{l}\text { Climb- } \\
\text { ers } \\
\text { present }\end{array}$ & & \\
\hline Tropical distribution & 48 & 5 & 181 & 131 & 24.4 & 0.000 \\
\hline Temperate distribution & 115 & 76 & 114 & 60 & 1.1 & 0.294 \\
\hline Monoecy & 168 & 65 & 61 & 71 & 23.9 & 0.000 \\
\hline Dioecy & 157 & 51 & 72 & 85 & 33.8 & 0.000 \\
\hline Abiotic pollination & 163 & 118 & 66 & 18 & 12.4 & 0.000 \\
\hline Biotic pollination & 47 & 10 & 182 & 126 & 12.4 & 0.000 \\
\hline Abiotic dispersal & 75 & 39 & 154 & 97 & 0.7 & 0.415 \\
\hline Biotic dispersal & 124 & 39 & 105 & 97 & 23.0 & 0.000 \\
\hline Herb growth form & 128 & 62 & 101 & 74 & 3.6 & 0.057 \\
\hline Shrub growth form & 133 & 45 & 96 & 91 & 21.7 & 0.000 \\
\hline Tree growth form & 118 & 72 & 111 & 64 & 0.1 & 0.794 \\
\hline Parasite habit & 220 & 132 & 9 & 4 & 0.2 & 0.617 \\
\hline
\end{tabular}

${ }^{a} \chi^{2}$ is the likelihood ratio $\chi^{2}$ value.

ond superorder. Families with the highest concentrations of dioecious genera in both absolute and relative terms are the Menispermaceae $(100 \%$ of the genera are dioecious), Myristicaceae (78\%), Moraceae (62\%), Urticaceae (52\%), Anacardiaceae (50\%), Monimiaceae (47\%), Euphorbiaceae (39\%), and Cucurbitaceae (32\%).

Among the subclasses, Cronquist (1988, pp. 263-265 and pp. 451-457) considers the Magnoliidae, Hamamelidae, and Caryophyllidae as less advanced than the Dilleniidae, Rosidae, and Asteridae among dicots, and the Alismatidae and Arecidae as relatively more primitive that the Commelinidae, Zingiberidae, and Liliidae among monocots. Dioecy is strongly concentrated in the less advanced subclasses. Also Thorne (1992, p. 244, fig. 1) tries to arrange his superorders so that "The position of these superordinal stem cross-sections of the phyletic shrub indicates as closely as possible my interpretation of their relationships and their relative degree of specialization from their more primitive, archaic ancestors." We have numbered the superorders in his sequence (Table 13) and divided the dicot superorders roughly into two groups, one relatively less advanced (numbers 1-9), the other relatively more advanced (numbers 10-19). As with Cronquist's subclasses, dioecy is concentrated in the less advanced superorders of dicots (genera: $\chi^{2}=519, P<0.0001$; families: $\chi^{2}=5.4, P<0.025$ ). Monoecious families have a parallel distribution to dioecious families (Table 13) and exhibit a similar concentration in less advanced dicot superorders $\left(\chi^{2}=4.4, P<0.05\right)$. Possible reasons for the concentration of dioecy in the less advanced clades are given in the discussion.

Geographic distribution of dioecious angiosperm genera-Of the 959 dioecious genera, 217 occur in the neotropics, 402 in the paleotropics, 86 are pantropical, and 149 are found exclusively in the temperate zone. Thirty genera have temperate and tropical members. The remaining 75 genera are mostly restricted to Hawaii, New Zealand, Australia, New Caledonia, or New South Wales. Because the total numbers of genera in the large geographic regions have not been tabulated, it is not possible to calculate the different relative frequencies of dioecy, but it seems likely that dioecy is indeed more frequent in the
TABLE 13. Distribution of dioecy in Thorne's (1992) superorders. Total numbers of genera in this table are from Thorne, while the families are circumscribed as in Cronquist (1988; see Methods).

\begin{tabular}{|c|c|c|c|c|c|c|c|}
\hline & & \multicolumn{3}{|c|}{$\begin{array}{c}\text { Number of } \\
\text { families }\end{array}$} & \multirow{2}{*}{$\begin{array}{c}\text { Total } \\
\text { number } \\
\text { of } \\
\text { genera }\end{array}$} & \multicolumn{2}{|c|}{ Dioecious genera } \\
\hline & Superorder & Total & $\begin{array}{l}\text { Dio- } \\
\text { ecious }\end{array}$ & $\begin{array}{l}\begin{array}{l}\text { Mono- } \\
\text { ecious }\end{array} \\
\text {. }\end{array}$ & & $\begin{array}{c}\text { Num- } \\
\text { ber }\end{array}$ & Percent \\
\hline \multicolumn{8}{|c|}{ Dicots } \\
\hline 1 & Magnolianae & 34 & 12 & 14 & 466 & 134 & 29 \\
\hline 2 & Nymphaeanae & 2 & 0 & 0 & 81 & 0 & 0 \\
\hline 3 & Rafflesianae & 3 & 1 & 1 & 10 & 8 & 80 \\
\hline 4 & Caryophyllanae & 12 & 9 & 7 & 563 & 30 & 5 \\
\hline 5 & Theanae & 40 & 14 & 10 & 540 & 58 & 19 \\
\hline 6 & Celastranae & 2 & 1 & 1 & 60 & 7 & 12 \\
\hline 7 & Malvanae & 20 & 17 & 12 & 769 & 208 & 27 \\
\hline 8 & Violanae & 26 & 13 & 11 & 725 & 90 & 12 \\
\hline 9 & Santalanae & 9 & 8 & 6 & 162 & 37 & 22 \\
\hline 10 & Geranianae & 16 & 4 & 3 & 189 & 7 & 4 \\
\hline 11 & Rutanae & 23 & 8 & 8 & 1,129 & 71 & 6 \\
\hline 12 & Proteanae & 1 & 1 & 1 & 75 & 2 & 2 \\
\hline 13 & Rosanae & 39 & 15 & 14 & 381 & 36 & 9 \\
\hline 14 & Cornanae & 23 & 16 & 11 & 650 & 44 & 7 \\
\hline 15 & Asteranae & 6 & 3 & 2 & 1,251 & 28 & 2 \\
\hline 16 & Solananae & 8 & 2 & 1 & 296 & 4 & 1 \\
\hline 17 & Loasanae & 1 & 0 & 0 & 13 & 0 & 0 \\
\hline 18 & Myrtanae & $13^{b}$ & 3 & 2 & 463 & 3 & 1 \\
\hline \multirow[t]{2}{*}{19} & Gentiananae & 23 & 5 & 6 & 2,135 & 49 & 2 \\
\hline & Total dicots & $305^{c}$ & 132 & 110 & 9,958 & $817^{\mathrm{c}}$ & 8 \\
\hline 20 & Lilianae & 15 & 8 & 2 & 1,184 & 16 & 1 \\
\hline 21 & Hydatellanae & 1 & 0 & 0 & 2 & 0 & 0 \\
\hline 22 & Triuridanae & 1 & 1 & 1 & 8 & 2 & 25 \\
\hline 23 & Alismatanae & 11 & 7 & 6 & 57 & 27 & 47 \\
\hline 24 & Aranae & 2 & 1 & 2 & 108 & 1 & 1 \\
\hline 25 & Cyclanthanae & 1 & 0 & 1 & 11 & 0 & 0 \\
\hline 26 & Pandananae & 1 & 1 & 0 & $3^{\mathbf{a}}$ & 3 & 100 \\
\hline 27 & Arecanae & 1 & 1 & 1 & 200 & 31 & 15 \\
\hline \multirow[t]{3}{*}{28} & Commelinanae & 26 & 6 & 9 & 1,192 & 62 & 5 \\
\hline & Total monocots & 60 & 25 & 22 & 2,765 & 142 & 5 \\
\hline & Total flowering plants & 365 & 157 & 132 & 12,723 & 959 & 7.5 \\
\hline
\end{tabular}

a Some Pandanaceae are monecious sex-changers rather than consistent dioecists (Cox, 1982).

b This number is inflated by Cronquist's recognition of Punicaceae and Sonneratiaceae as distinct from Lythraceae.

c Including four of Cronquist's families that are unassigned by Thorne: Aextoxicaceae, Barbeyaceae, Corynocarpaceae, and Pandaceae; of these, Aextoxicon and Barbeya are dioecious.

Old World tropics than in the New as suggested by Thomas and LaFrankie (1993), due primarily to the high Old World diversity of such dioecy-rich families as the Euphorbiaceae, Menispermaceae, and Restionaceae.

Growth forms of dioecious angiosperm genera-We have information on the growth forms of 818 of the 959 genera with dioecy. Of the $818,198(24 \%)$ comprise only tree species, $157(19 \%)$ only herbs, $128(16 \%)$ only climbers, and $94(11 \%)$ only shrubs. Tree and shrub species occur together in $195(24 \%)$ genera with dioecy. Other combinations of growth forms, such as trees, shrubs, and herbs (seven genera), shrubs and herbs (19 genera), shrubs and climbers (ten genera), and so on are rare. Of the genera with dioecy, $\approx 551(67 \%)$ are woody (namely those with trees and shrubs or both growth forms, plus half those with only climbers). In the angiosperms as a whole, 234 families including tree and shrub growth forms have 7,929 genera, or $59 \%$ of the total 13,500 genera; 182 families 
TABLE 14. Genus-level analysis of the association between dioecy and pollinators.

\begin{tabular}{lcc}
\hline \hline & \multicolumn{2}{c}{ Number of genera } \\
\cline { 2 - 3 } \multicolumn{1}{c}{ Pollinated by } & With dioecy & Lacking dioecy \\
\hline Insects & $550(5.1 \%)$ & $10,317^{\mathrm{a}}$ \\
Wind or water & $232(21.0 \%)$ & 874 \\
Bats or birds & $4(0.4 \%)$ & 750 \\
\hline
\end{tabular}

a This number of nondioecious genera pollinated by insects was arrived at by subtracting from the total number of angiosperm genera $(13,500)$ all the dioecious genera (959), 750 bird- and bat-pollinated genera, 874 genera in families with solely wind- or water-dispersed members, and an estimated 600 genera in families with various dispersal modes. There are $\approx 250$ bat-pollinated genera (Dobat and Peikert-Holle, 1985 ) and 500 bird-pollinated genera (Porsch, 1931 and our own estimate).

having only shrubs or trees have 3,185 genera, or $24 \%$ of the total angiosperm genera. Thus, between $24 \%$ and $59 \%$ of all angiosperm genera may be woody, and so woodiness would appear to be overrepresented among dioecious genera. In the family-level analysis, woodiness per se was not a factor because the tree growth form had no influence on the presence or absence of dioecy within a family and the shrub growth form had an effect only in some of the analyses (but see Materials and Methods for a discussion of the limitations of a multivariate approach at the family level).

Dioecy and trophic condition-Of the 959 dioecious genera, at least $43(4 \%)$ are holoparasites, hemiparasites, or saprophytes. Dioecious parasites occur in the Balanophoraceae, Eremolepidaceae, Loranthaceae, Misodendraceae, Opiliaceae, Rafflesiaceae, Santalaceae, and Viscaceae. Among the remainder of the angiosperms, parasitic genera are concentrated in the Convolvulaceae (Cuscutoideae), Cynomoriaceae, Hydnoraceae, Krameriaceae, Lennoaceae, Loranthaceae, Olacaceae, Santalaceae, Scrophulariaceae (Rhinanthoideae, Orobanchoideae), and Rafflesiaceae (Mitrastemonoideae), which together may comprise some 135 heterotrophic genera $(1.1 \%$ of all 13,500 angiosperm genera). Dioecy therefore may be overrepresented among heterotrophic plants. This was also suggested by a species-level analysis of dioecy in the flora of the southeastern United States (Conn, Wentworth, and Blum, 1980); $\approx 17 \%$ of all the Carolina heterotrophs are dioecious.

Pollination modes of dioecious angiosperm genera-Of the 799 genera with dioecious species for which there are sufficient data on the mode of pollination, $232(30 \%)$ are wind- or water-pollinated, $550(68 \%)$ are predominantly insect-pollinated, and $14(2 \%)$ have wind and insect pollination in closely related species and sometimes within a species. Three genera, the Liliaceae Collospermum and Astelia (Dobat and Peikert-Holle, 1985) and the Balanophoraceae Dactylanthus (Webb and Kelly, 1993), are pollinated by bats. Another bat-pollinated but trioecious species is Pachycereus pringlei (Cactaceae; Flemming, personal communication). Freycinetia (Pandanaceae) is pollinated by birds and bats (Cox, 1982). When these figures are compared to the $\approx 250$ genera with bat-pollinated species (Dobat and Peikert-Holle, 1985) and 500 genera with bird-pollinated species (Porsch, 1931; and personal estimate) in the rest of the flowering plants (Table 14) it appears that insect and vertebrate pollination are both underrepresented among dioecious genera. This was also noted by, for example, Richards (1986); below we discuss possible reasons for the near absence of bat pollination among dioecists.

Dispersal modes of dioecious angiosperm genera-Of the 814 dioecious genera for which there are sufficient data on mode of dispersal, $526(65 \%)$ are entirely or predominantly animal-dispersed, 254 (31\%) are dispersed by wind, 28 are water-dispersed, and six have both biotic and abiotic modes of dispersal. We have no data on the dispersal modes of 145 genera. In the family-level data set, 1,782 genera belong to 114 families with wholly biotic dispersal and 5,362 genera belong to 88 families with both abiotic and biotic dispersal. Taking half the latter plus the former gives an estimate of 4,463 animal-dispersed genera, or $\approx 33 \%$ of the angiosperm total. As in the case of woody growth, animal dispersal appears to be overrepresented among dioecious genera, even though this was not a particularly strong factor in the family-level analysis.

\section{DISCUSSION}

As has often been pointed out, the scattered systematic distribution of dioecy in the angiosperms suggests that this mating system has evolved independently many times and possibly for different reasons (Lewis, 1942; van der Pijl, 1978; Lloyd, 1982). This is also suggested by the fact that in some lineages, such as the Caryophyllaceae and Chenopodiaceae, sexual expression varies almost continually, with ready suppression of male or female function in response to environmental conditions (Heslop-Harrison, 1957; Freeman, McArthur, and Harper, 1984; Freeman et al., 1993), while in other lineages, such as the Monimiaceae, Euphorbiaceae, and Cucurbitaceae, dicliny is basically fixed. In the dicotyledonous angiosperms as a whole, monoecy and dioecy are concentrated in the less advanced superorders of Thorne (1992). A consequence of this nonrandom distribution is that frequencies of dioecy in particular floras (made much of by many authors) likely reflect the level of dioecy in a particular pool of families as much as, or more than, local selective factors. Therefore, the question regarding which of the various ecomorphological features associated with dioecy play a causal role, and under which circumstances, will have to be answered for a number of individual lineages before we can extrapolate from common features to common causes.

To control for phylogenetic resemblances between members of the same lineage, we are currently analyzing our dioecy data set within the framework of recently published molecular phylogenies (Renner, unpublished data). However, as suggested by D. Charlesworth (letter of 16 March 1994) the differences between and similarities within lineages should tend to obscure general patterns; so, where general patterns are nevertheless apparent we can accord them some weight.

At the family level, the correlation between dioecy and fleshy fruits (biotic dispersal) is significant but does not account for a large proportion of the variation among 
families in presence or absence of dioecy; at the generic level, biotic dispersal appears to be overrepresented among dioecists. The association of dioecy with fleshy fruits found in particular floras (see the introduction) likely reflects the combined effects of local sampling and multiple associations among the correlates themselves. Thus, for example, across all angiosperms fleshy fruits are strongly correlated with the tree growth form (Ricklefs and Renner, in press), which in turn predominates in certain tropical families.

Tree growth alone is not associated with dioecy at the family level, while the shrub growth form has a weak positive effect only in some analyses; climbing growth, whether woody or herbaceous, by contrast has a strong enhancing effect on the presence of dioecy (possibly mechanisms for this association are suggested below). The supposed correlation between woodiness per se and dioecy has led various authors (e.g., Lloyd, 1982) to hypothesize about a particular need for obligatory outbreeding in longlived, woody plants due to genetic loads. Another suggestion relates woodiness and dioecy via the more intense selection for heterosis in the climax habitats where these plants occur (Bell, 1982). The present analysis provides little empirical justification for these hypotheses.

Dioecy is strongly associated with monoecy, abiotic pollination, and climbing growth. We will now address possible mechanisms underlying these three associations. The single most important predictor of a group's tendency to acquire dioecy is the presence of monoecy in the group (as also found by Yampolsky and Yampolsky, 1922, and Lewis, 1942). As pointed out by Westergaard (1958), the general direction of evolutionary change is likely to be from monoecy to dioecy; clearly, however, phylogenetic analyses of individual examples are needed to support this assumption. The route from monoecy to dioecy may be especially common because once a lineage has the physiological and morphological ability to suppress male or female function in some flowers, the subsequent step to dioecy may occur through divergent adjustments of floral sex ratios between individual plants (Lloyd, 1972; McArthur et al., 1992). It may be easier for strictly monoecious populations to evolve dioecy (since mutations affecting pollen and ovule production must already have occurred in their unisexual flowers) than for populations that produce bisexual flowers, be they gynomonoecious, andromonoecious, polygamo-monoecious, gynodioecious, androdioecious, or trioecious. Indeed, how frequently gynodioecy has led toward dioecy is unclear (Charlesworth and Charlesworth, 1978; Gouyon and Couvet, 1987; Weller and Sakai, 1991; Barrett, 1992).

Why are dioecy and monoecy concentrated in the less advanced dicots in spite of the fact that very few of the most primitive extant Magnoliidae are wind-pollinated (Endress, 1990a)? We believe that the reason has to do with floral morphological constraints, or, rather, their absence. In primitive angiosperms, floral phyllotaxis is relatively plastic, and there is little integration between male and female floral parts (Endress, 1987, 1990b). In the more advanced groups, by contrast, numbers of floral parts often are low and fixed, and structures have evolved to direct pollinator movement or to conceal nectar (usually via perigyny or epigyny, sympetaly, and zygomorphy). Apocynaceae, Asclepiadaceae, Brunoniaceae, Calycera- ceae, Campanulaceae, Goodeniaceae, Lobeliaceae, and other families in the Asteridae exhibit a complex synorganization of male and female organs, for example, with pollen first being deposited on and then presented by the style (secondary pollen presentation) or with congenital and postgenital fusion of carpels, petals, and stamens. A similar synorganization of male and female structures characterizes many Fabaceae (for further examples, see van der Pijl, 1978). All this should make the ontogenic suppression of male or female organs, without radical alterations in the structural organization of the flower, more difficult in the more advanced groups than in the less advanced ones.

Modern families that have managed to escape from such constraints are, e.g., the Apiaceae, Araliaceae, and Asteraceae (the latter in spite of secondary pollen presentation), all of which have small flowers aggregated into inflorescences and all of which are capable of suppressing sexual function in some flowers. They have andromonoecious and gynomonoecious species, yet relatively little dioecy (six of 403 genera and $\approx 34$ of 3,100 species in the Apiaceae, four of 47 genera and $\approx 69$ of 800 species in the Araliaceae, and 26 of 1,509 genera, and $\approx 526$ of 20,000 species in the Asteraceae).

A second correlate of dioecy (and monoecy) is pollination by wind or water. Several causative factors for the association between dioecy and abiotic pollination have been suggested (Darwin, 1876; Kerner, 1895; van der Pijl, 1978; Freeman, Harper, and Ostler, 1980). In wind-pollinated plants, pollen release may require pendulous, shaking stamens whereas pollen capture may favor large, erect, free stigmas. Similarly, hydrophilous plants have floral mechanisms for the capture of water-borne pollen that physically interfere with mechanisms for the dispersal of pollen (Cox, 1988, 1991). Also, the imprecise movement of pollen by wind or water is likely to cause frequent selfing (in the absence of self-incompatibility) in an hermaphrodite. Therefore, abiotic pollination should favor unisexual flowers, the latter then apparently facilitating the evolution of dioecy from monoecy. Support for such an interpretation comes from relatively few studies of changes in breeding system in connection with changes in pollination mode. In Acer (Hesse, 1979) and Thalictrum (Kaplan and Mulcahy, 1971) a switch in some species from insect to wind pollination accompanied the acquisition of dicliny, polygamodioecy, and dioecy; while Hesse interprets anemophily to have preceded dicliny in Acer, Kaplan and Mulcahy favor the opposite interpretation in Thalictrum. Phylogenetic studies may eventually permit us to establish the evolutionary sequence of events in both genera. In tropical, entomophilous Fagaceae, dicliny and monoovuly may have been preadaptive to a later acquisition of anemophily as suggested by van der Pijl (1978). In still other groups, the transition from bisexual to unisexual flowers was not associated with a switch from insects to wind, and in these taxa, insect pollination may have something to do with the evolution of dioecy, although the mechanism for such an effect (increased selfing rates in parts of the range with different pollinator behavior?) is unclear.

Thirdly, dioecy is strongly associated with climbing growth, irrespective of whether the plant is a woody liana or an herbaceous vine. Families with climbers, as a group, 
seem to have a combination of features predisposing them to dioecy, namely high incidence of monoecy, fleshy fruits, and tropical distribution. However, the positive effect of the climbing habit on a family's likelihood of comprising dioecious species is independent of these other variables (Table 2). We suspect differential selection for optimal resource allocation to sexual function to be responsible for this effect. An increase in female floral allocation with increased plant size has been found in several monoecious climbers (Bickel and Freeman, 1993). This implies resource limitations to fruit set below a certain threshold, and in Cucurbita pepo subsequent growth is indeed strongly inhibited after the first fruit is produced (Nitsch et al., 1952). If rapid upward growth is at a premium in climbers and if fruit set at least temporarily inhibits growth or requires the production of a thick, slowly growing stem to support heavy fruits, it might be advantageous to postpone femaleness. If the effect is strong, this may favor male plants. Structural necessities may also favor separation of the sexes, with flowers bearing fruit better placed on thicker stems and pollen-dispensing flowers on thinner, more exposed modules.

The near absence of bird and bat pollination among dioecious plants (Table 14) may be explained by the fact that vertebrate pollination requires adaptations of floral morphology, which seems to almost preclude the evolution of dicliny. First, pollination by large-bodied animals, such as birds and bats, requires large quantities of nectar (Opler, 1983), which can be offered adequately only in cups, tubes, or spurs typically formed by concave floral receptacles (often with inferior ovaries) and/or fused petals (sympetaly). Secondly, pollination by these vectors requires relatively large quantities of pollen, which are often produced by numerous stamens (secondary polyandry). Inferior ovaries, sympetaly, and secondary polyandry are attributes of the relatively advanced subclasses Dilleniidae, Rosidae, and Asteridae, but nearly absent in the Magnoliidae and Hamamelidae (Cronquist, 1988; Endress, 1990b). Thus there is a strong morphological constraint on vertebrate pollination. Indeed, of the circa 250 genera with bat-pollinated species known in the angiosperms (Dobat and Peikert-Holle, 1985), none belong to the Magnoliidae and Hamamelidae, while $28 \%$ are in the Rosidae, 26\% in the Asteridae, 25\% in the Dilleniidae, $13 \%$ in the monocots, and $8 \%$ in the Caryophyllidae. The distributions of bat pollination and dioecy in the angiosperms are thus almost mutually exclusive.

While the environmental conditions under which populations change breeding systems will have to be addressed experimentally in alliances with relatively labile sex expression, such as Begonia, Atriplex, or Wurmbea (Barrett, 1992; McArthur et al., 1992), the global analysis performed here suggests that across all angiosperm families monoecy, wind pollination, and climbing growth consistently favor the evolution of dioecy. Other traits, such as heavy, fleshy fruits, may play a role in certain lineages. Where the ontogenetic floral adjustments required for unisexual flowers are possible without jeopardizing pollination, specialization for one sexual function appears favored by selection under a wide range of environmental conditions as is apparent from our finding that geographic distribution has no strong effect on presence or absence of dioecy.

\section{LITERATURE CITED}

BAKER, H. 1959. Reproductive methods as factors in speciation in flowering plants. Cold Spring Harbor Symposium in Quantitative Biology 24: 177-191.

BARRETT, S. C. H. 1992. Gender variation and the evolution of dioecy in Wurmbea dioica (Liliaceae). Journal of Evolutionary Biology 5: $423-444$.

BAwA, K. S. 1980. Evolution of dioecy in flowering plants. Annual Review of Ecology and Systematics 11: 15-39.

- 1994. Pollination of tropical dioecious angiosperms: a reassessment? No, not yet. American Journal of Botany 81: 456-460. , AND P. A. OPLer. 1975. Dioecism in tropical forest trees. Evolution 29: 167-179.

BeLL, G. 1982. The masterpiece of nature. Croom Helm, London.

BiCKel, A. M., AND D. C. FreEmAN. 1993. Effects of pollen vector and plant geometry on floral sex ratio in monoecious plants. American Midland Naturalist 130: 239-247.

BRUMMITT, R. K. 1992. Vascular plant families and genera. Royal Botanic Gardens, Kew.

Charlesworth, B., AND D. Charlesworth. 1978. A model for the evolution of dioecy and gynodioecy. American Naturalist 112: 975 997.

Charlesworth, D. 1985. Distribution of dioecy and self-incompatibility in angiosperms. In P. J. Greenwood and M. Slatkin [eds.], Evolution: essays in honour of John Maynard Smith, 237-268. Cambridge University Press, Cambridge.

Conn, J. S., T. R. Wentworth, AND U. Blum. 1980. Patterns of dioecism in the flora of the Carolinas. American Midland Naturalist 103: 310-315.

Cox, P. A. 1982. Vertebrate pollination and the maintenance of dioecism in Freycinetia. American Naturalist 120: 65-80.

- 1988. Hydrophilous pollination. Annual Review of Ecology and Systematics 19: 216-280.

. 1990. Pollination and the evolution of breeding systems in Pandanaceae. Annals of the Missouri Botanical Garden 77: 816840.

. 1991. Abiotic pollination: an evolutionary escape for animalpollinated angiosperms. Philosophical Transactions of the Royal Society of London B 333: 217-224.

- 1993 . Hydrophilous pollination and breeding system evolution in seagrasses: a phylogenetic approach to the evolutionary ecology of Cymodoceaceae. Botanical Journal of the Linnean Society 113: 217-226.

CroAt, T. B. 1979. The sexuality of the Barro Colorado Island flora (Panama). Phytologia 42: 319-348.

Cronouist, A. 1988. The evolution and classification of flowering plants, 2d ed. Columbia University Press, New York, NY.

DARWIN, C. 1876. The effects of cross and self fertilisation in the vegetable kingdom. John Murray, London.

Dobat, K., AND T. Peikert-Holle. 1985. Blüten und Fledermäuse. Verlag von Waldemar Kramer, Frankfurt.

Donoghue, M. J. 1989. Phylogenies and the analysis of evolutionary sequences, with examples from seed plants. Evolution 43: 11371156.

ENDRESS, P. K. 1987. Floral phyllotaxis and floral evolution. Botanische Jahrbücher für Systematik 108: 417-438.

-1990a. Evolution of reproductive structures and functions in primitive angiosperms (Magnoliidae). Memoirs of the New York Botanical Garden 55: 5-34.

- 1990b. Patterns of floral construction in ontogeny and phylogeny. Biological Journal of the Linnean Society 39: 153-175.

Fox, J. F. 1985. Incidence of dioecy in relation to growth form, pollination and dispersal. Oecologia 67: 244-249.

Freeman, D. C., K. T. HARPER, AND W. K. OstLer. 1980. Ecology of plant dioecy in the intermountain region of Western North America and California. Oecologia 44: 410-417.

- E. D. MCARTHUR, AND K. T. HARPER. 1984. The adaptive significance of sexual lability in plants using Atriplex canescens as a principal example. Annals of the Missouri Botanical Garden 71: 265-277. 
influence of topography on male and female fitness components of Atriplex canescens. Oecologia 93: 538-547.

GENTRY, A. 1991. The distribution and evolution of climbing plants. In F. E. Putz and H. A. Mooney [eds.], The biology of vines, 349. Cambridge University Press, Cambridge.

GivNISH, T.J. 1980. Ecological constraints on the evolution of breeding systems in seed plants: dioecy and dispersal in gymnosperms. Evolution 34: 959-972.

GouYon, P.-H., AND D. Couvet. 1987. A conflict between two sexes, females and hermaphrodites. In S. C. Stearns [ed.], The evolution of sex and its consequences. Birkhäuser Verlag, Basel.

HART, J. A. 1985. Evolution of dioecism in Lepechinia Willd. sect. Parviflorae (Lamiaceae). Systematic Botany 10: 147-154.

HesLoP-HARRISON, J. 1957. The experimental modification of sex expression in flowering plants. Biological Reviews of the Cambridge Philosophical Society 32: 38-90.

Hesse, H. 1979. Ultrastruktur und Verteilung des Pollenkitts in der insekten- und windblütigen Gattung Acer (Aceraceae). Plant Systematics and Evolution 131: 277-289.

IbARRA-MANRÍQUEZ, G., AND K. OYAMA. 1992. Ecological correlates of reproductive traits of Mexican rain forest trees. American Journal of Botany 79: 383-394.

KaPlan, S. M., AND D. L. MulCaHY. 1971. Mode of pollination and floral sexuality in Thalictrum. Evolution 25: 659-668.

KATo, M. 1993. Floral biology of Nepenthes gracilis (Nepenthaceae) in Sumatra. American Journal of Botany 80: 924-927.

Kerner von Marilaun, A. 1895. Pflanzenleben, vol. 2. Bibliographisches Institut, Leipzig.

KubitzKi, K., J. G. RohwER, AND V. BitTrich [eds.]. 1993. The families and genera of vascular plants, vol. 2. Springer-Verlag, Berlin.

Lahay-Ginotr, S., AND Q. C. B. Cronk. 1993. The mating system of Elatostema (Urticaceae) in relation to morphology: a comparative study. Plant Systematics and Evolution 186: 135-145.

LewIS, D. 1942. The evolution of sex in flowering plants. Biological Review of the Cambridge Philosophical Society 17: 46-67.

LLoYd, D. G. 1972. Breeding systems in Cotula L. (Compositae, Anthemideae). New Phytologist 71: 1181-1194.

- 1982. Selection of combined versus separate sexes in seed plants. The American Naturalist 120: 571-585.

MabberLey, D. J. 1987. The plant-book. Cambridge University Press, Cambridge.

McArthur, E. D., D. C. Freeman, L. S. Luckinbill, S. C. Sanderson, AND G. L. Noller. 1992. Are trioecy and sexual lability in Atriplex canescens genetically based?: evidence from clonal studies. Evolution 46: 1708-1721.

МсСомB, J. A. 1966. The sex forms of species in the flora of the south-west of western Australia. Australian Journal of Botany 14: 303-316.

MuENCHOw, G. E. 1987. Is dioecy associated with fleshy fruit? American Journal of Botany 74: 287-293.
Nitsch, J. P., E. B. Kurz, J. L. Liverman, AND F. W. Went. 1952. The development of sex expression in cucurbit flowers. American Journal of Botany 39: 32-43.

OPLER, P. A. 1983. Nectar production in a tropical ecosystem. In B. Bentley and T. Elias [eds.], The biology of nectaries, 30-79. Columbia University Press, New York, NY.

PorsCH, O. 1931. Grellrot als Vogelblumenfarbe. Biologia Generalis 7: 647-674.

Renner, S. S., AND J. P. FeIL. 1993. Pollinators of tropical dioecious angiosperms. American Journal of Botany 80: 1100-1107.

RiCHARDS, A. J. 1986. Plant breeding systems. Allen and Unwin, Winchester, MA.

RICKLEFS, R. E., AND S. S. ReNNER. 1994. Species richness within families of flowering plants. Evolution 48 , in press.

SAS INSTITUTE, INC. 1988. SAS/STAT (TM) user's guide, Release 6.03 ed. SAS Institute, Inc., Cary, NC.

SPORNE, K. R. 1949. A new approach to the problem of the primitive flower. New Phytolologist 48: 259-276.

Stebbins, G. L. 1950. Variation and evolution in plants. Columbia University Press, New York, NY.

. 1951. Natural selection and the differentiation of angiosperm families. Evolution 5: 299-324.

STEINER, K. E. 1988. Dioecism and its correlates in the Cape flora of South Africa. American Journal of Botany 75: 1742-1754.

Thomas, S. C., AND J. V. LAFrankIE. 1993. Sex, size, and interyear variation in flowering among dioecious trees of the Malayan rain forest. Ecology 74: 1529-1537.

Thomson, J. D., AND S. C. H. BARRETT. 1981. Selection for outcrossing, sexual selection, and the evolution of dioecy in plants. American Naturalist 118: 443-449.

- AND J. BRUNET. 1990. Hypotheses for the evolution of dioecy in seed plants. Trends in Ecology and Evolution 5: 11-16.

THORNE, R. F. 1992. Classification and geography of the flowering plants. Botanical Review 58: 225-348.

VAN DER PIIL, L. 1978. Reproductive integration and sexual disharmony in floral functions. In A. J. Richards [ed.], The pollination of flowers by insects, 79-88. Academic Press, London.

WebB, C. J., AND D. Kelly. 1993. The reproductive biology of the New Zealand flora. Trends in Ecology and Evolution 8: 442-447.

Webster, G. L. 1994a. Classification of the Euphorbiaceae. Annals of the Missouri Botanical Garden 81: 3-32.

1994b. Synopsis of the genera and suprageneric taxa of Euphorbiaceae. Annals of the Missouri Botanical Garden 81: 33-144.

Weller, S. G., AND A. K. SAKAI. 1991. The genetic basis of male sterility in Schiedea (Caryophyllaceae), an endemic Hawaiian genus. Heredity 67: 265-273.

WeSTERGAARD, M. 1958. The mechanism of sex determination in dioecious flowering plants. Advances in Genetics 9: 217-281.

YAMPOLSKY, C., AND H. YAMPOLSKY. 1922. Distribution of sex forms in the phanerogamic flora. Bibliotheca Genetica 3: 1-62. 